\title{
Editorial
}

\section{The Role and Responsibility of Peer Review}

This is the last editorial in the series addressing evolving models of peer review. Throughout the year, we have explored different ways in which peer review manifests - in journal articles, in research data, and in professional practice. It has generated conversations about peer review and its relevance in current scholarship and practice, both positive and critical. There have been conversations and comments about the "flaws of traditional peer review." I hope that these are opportunities for dialogue and growth within the peer review process. Some of the concerns may be around the "traditional" models possibly perceived as driven by commercial publishers and anathema to open access. Or perhaps it is the opinion that peer review perpetuates an elitist framework around "quality." Or it may be that the process is not transparent enough and thus, provokes skepticism. Each is a valid perspective. Hopefully, though, the conversation does not stop there.

So I want to come back to what peer review is and why it exists. The primary value of peer review is two-fold: first, the assessment - both objective and expert-of new knowledge or practice to signify research that contributes innovation and new knowledge to scholarship and practice in a profession or a discipline; and, second, the indicator of quality and objectivity that this process provides to practitioners, scholars, and students about the information. This second point has become even more critical with the plethora of information available and the lack of critical indicators to determine what is valid. The true value of peer review is that communities of scholarship are in the best position to identify what innovation and rigor look like within their own discipline - this standard is not externally imposed. It is not a star chamber with a bunch of administrators or distinguished professors raking researchers and scholars over the coals in an effort to shore up their own power and marginalize those who might seek change.

The stewards of peer review are us. It is you. It is your peers and colleagues and the people whose work you like to read, build on, and put into practice. The reviewers are made up of scholars and practitioners who have demonstrated experience with scholarly publishing and have an area of specialization or expertise within the scope of the journal. We are all participants in the process of peer review and we are the beneficiaries of that system. It does not mean that it should remain unchanged. It should evolve with the profession and those within it should feel empowered to help it evolve while still maintaining those high standards that signify the integrity of the research and the process.

There are probably those who would argue that I am not elitist enough as, under my editorship, the number of reviewers for $C \mathcal{E} R L$ has increased more than 3 times. The reviewers are distinct from the Editorial Board although, as I have said before, I like to see a demonstration of commitment to the efforts of $C \mathcal{E} R L$ before I recommend appointment to the editorial board-and being a reviewer is a prime way to do that. $C \mathcal{E} R L$, due to the volume and the breadth of submissions, has about 132 reviewers who contribute to the work of the journal. The selection process is fairly straightforward-peer reviewers have been chosen in a few ways: either, an individual contacts the editor or fills out the ALA volunteer form, indicating interest in working with the journal; the editor may extend an invitation after reviewing their publication expe- 
rience; or a library scholar is chosen based on the expertise needed for the journal, often due to an emerging area or an abundance of submissions on a topic. In selecting reviewers for the journal, demographics are not currently taken into consideration at all. In fact, other than the data included in the journal management system (reviewer name, address, institutional affiliation, and chosen topical areas), we don't collect any information about the reviewers beyond their peer review activity.

The latest issue of College \& Research Libraries News, reports the findings of a survey of editorial boards across the Association of College \& Research Libraries. This was the result of discussions around diversity, representation, and inclusion on the Association's Publications Coordinating Committee. Even though the College \& Research Libraries editorial board participated in the initial survey, the results were intriguing enough that they prompted me to send the survey out to all of the reviewers who volunteer for $C E R L$. It was heartening that, of the 132 C\&RL reviewers sent the survey, 91 responded.

The results of the reviewer survey are fairly consistent with those of the previous editorial board survey. The age range for the $C \mathcal{E} R L$ reviewers compared to the editorial boards trends older although the median for both groups is at the 41 to 50 range.

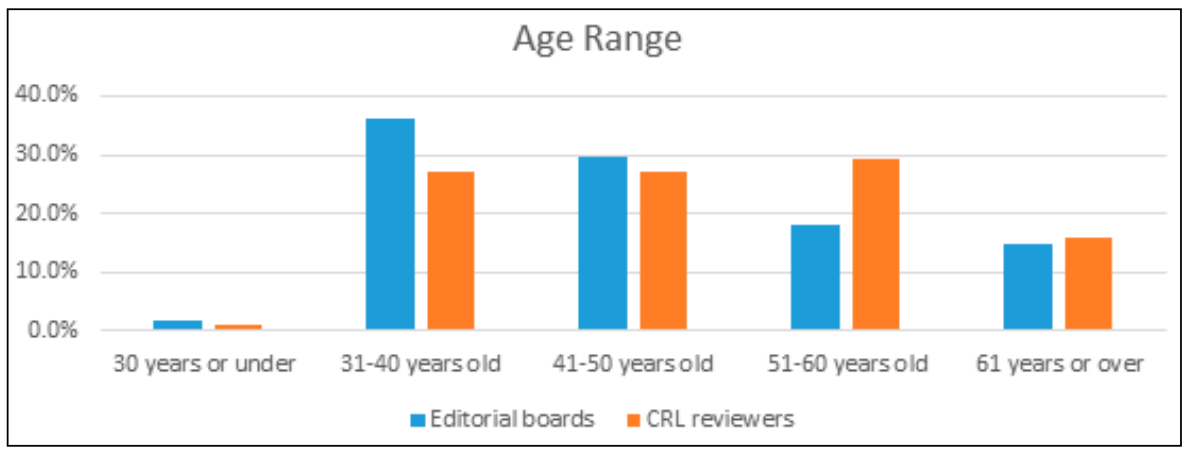

Interestingly, there is some departure between the editorial boards and the CERL reviewers when comparing the data on the number of years of experience as a librarian; the median years of experience for the editorial boards is 11 to 15 years while the reviewers reported 16 to 20 as the median.

The gender of the $C \mathcal{E} R L$ reviewers is about a 2-to 1-ratio with a higher percentage identifying as male than either the editorial board survey or the Diversity Counts data (which, incidentally, is based on 2009-2010 ACS data).

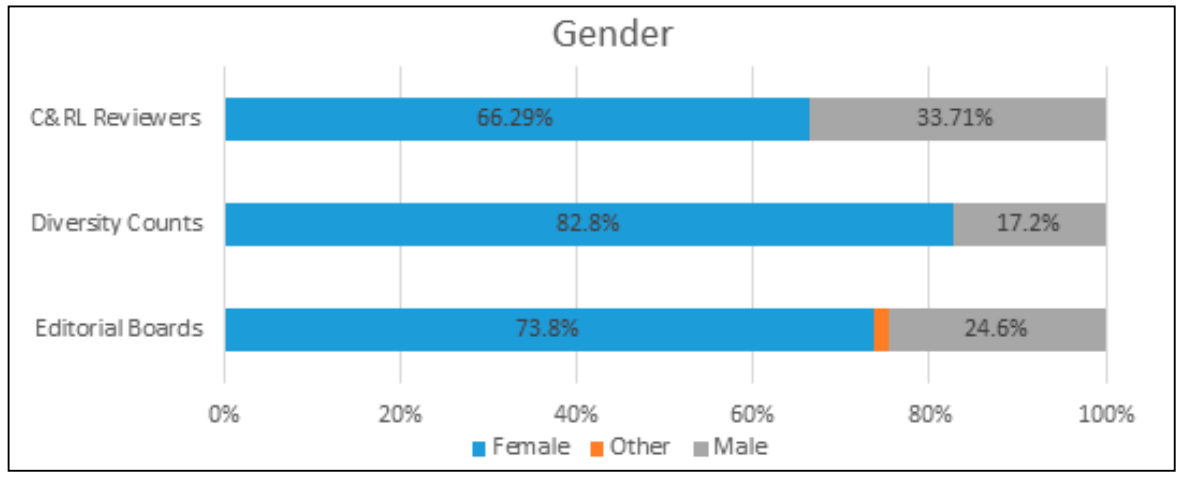


This is interesting to me because a large number of reviewers were invited by virtue of having published previously with $C \mathcal{E} R L$. The results might warrant a study of the demographics of authors and acceptances and what it might signify.

The ethnicity, comparable to the Editorial Board survey, is predominantly white and not out of line with the profession as a whole as indicated by the Diversity Counts data.

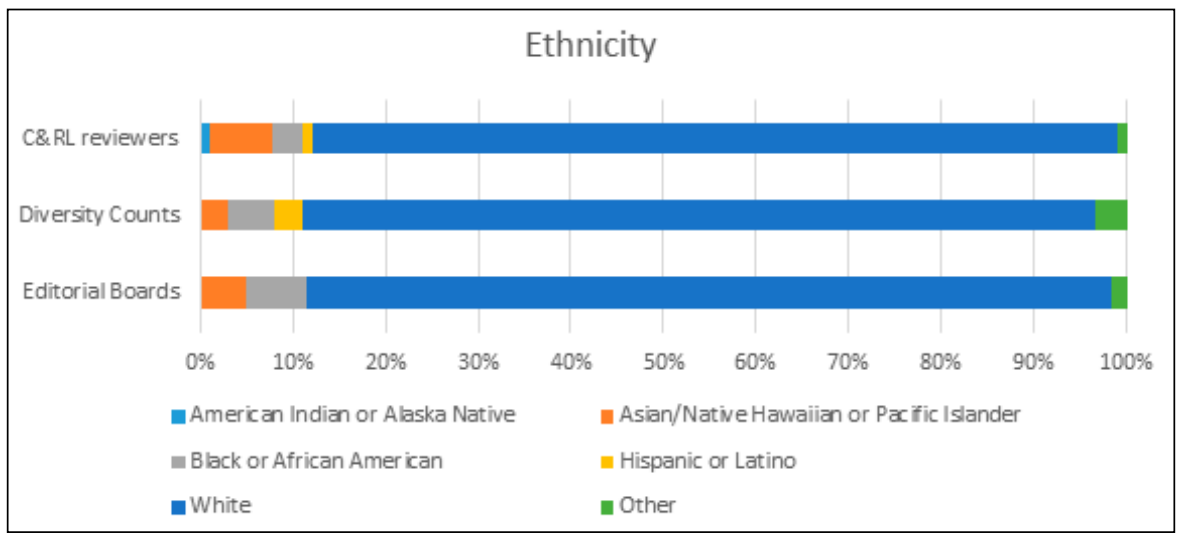

However, one of the questions that I ask myself as I look at the results is "Are the results representative?" That seems like a straightforward question but it really is anything but. Probably the more significant question is, what do the results represent? Is it the ACRL membership? Is it academic librarians in the US? At large? And an even more compelling question is, "What should it represent?" Should it be representative of institutions in higher education and the body of students who are, arguably, the reason for the existence of academic libraries?

If we look at that last question - how representation aligns with demographics in institutions of higher education - then there is, I would postulate, a huge discrepancy. There may be all sorts of arguments about academic librarians not needing to concern themselves with being representative of the student bodies they serve-most institutions don't have library schools so the student-librarian interaction is not as scrutinized as the one between student and teacher. But there is one argument that is particularly powerful-and it is not one of mine. It is the outcry that many students at institutions of higher education made during protests in response to incidents of police violencehow come the faculty at my college, my university, don't look like me? Again, it may be that our contribution is less significant and "they are not talking about us." Or, it could be that talking the talk is enough. While libraries and librarians have also engaged on this issue and advocated for social justice, we have an opportunity to take a more responsible role and to actually model what we espouse.

I would also argue that librarians actually have more responsibility than your average faculty member to be responsive to issues of inclusion and diversity. This is because we do talk the talk - freedom and access are foundational values to the profession. It is also true that librarians are in a unique, and enviable, position with students the perception that we are fair and impartial, that we deal in facts, that our job is to help and empower students with regard to their information, research and curriculum efforts, and that we are perceptibly discipline agnostic-such that we have their trust and the potential to reach a lot more students. With this kind of influence, we need to do more than engage in the conversation. We need to look at what we can do to actively reach out to students, to encourage and mentor them, and to attract diverse 
experiences and minds to the profession. And when I say we, I mean each individual librarian, when they get the chance to engage should do so. Association level programs are all well and good - but just as each of us can probably point to the individual who was an influence in our decision to choose librarianship, so too can each of us be that person for a student today.

So, I digressed into a big sticky, societal issue-but what does this mean for College $\mathcal{E}$ Research Libraries? As the editor and current steward of the journal, I feel that I also have responsibility to engage on this issue. To that end, I offer a thought-provoking (and possibly confrontational) question-Is there a role and a responsibility to move from advocating diverse representation to a more activist effort by taking a leadership role to model what we would like the profession to look like? I do not have answers, merely questions - but I welcome future dialogue and discussion on this issue. 